\title{
Stereoselective synthesis and sialidase inhibition properties of KDO-based glycosyloxathiins
}

\author{
Barbara Richichi, ${ }^{\text {a }}$ Jennifer McKimm-Breschkin, ${ }^{\mathrm{b}}$ Veronica Baldoneschi, ${ }^{\text {a }}$ \\ and Cristina Nativi ${ }^{\text {a }}$ \\ a Dipartimento di Chimica "Ugo Schiff”, University of Florence, via della Lastruccia, 13 \\ I-50019 Sesto Fiorentino (FI), Italy \\ ${ }^{b}$ CSIRO Materials Science and Engineering, 343 Royal Parade, Parkville, 3052 Australia \\ E-mail: barbara.richichi@unifi.it
}

\section{Dedicated to Professor Pierre Vogel on the occasion of his $70^{\text {th }}$ anniversary}

\section{DOI:http://dx.doi.org/10.3998/ark.5550190.p008.395}

\begin{abstract}
The stereoselective synthesis of KDO-based glyco-1,4-oxathiins is described. Relying on a totally diastereoselective inverse electron demand hetero Diels-Alder, $\alpha, \alpha^{\prime}$-dioxothiones as electron-poor heterodienes, and glycals as electron-rich dienophiles, reacted to give, in high yield, the KDO-based glyco derivatives 11 and 12a-c. Taking into account their structural features, biological tests have been run to evaluate the properties of $\mathbf{1 1}$ and 12a as sialidase inhibitors. The synthetic and biological data reported confirmed the versatility of this powerful [4+2] cycloaddition and showed the KDO-based cycloadduct $\mathbf{1 1}$ as attractive scaffold for the development of new sialidase inhibitors.
\end{abstract}

Keywords: Hetero Diels-Alder, KDO, exo-glycal, $\alpha, \alpha^{\prime}$-dioxothiones, sialidase inhibitors, selective synthesis

\section{Introduction}

Pericyclic reactions represent one of the most powerful tools in synthetic chemistry. These reactions have been widely employed to obtain regio- and stereoselectively complex molecules with high atom economy degree. Among these, the inverse electron demand [4+2] Diels-Alder reactions (iEDDA) gained a great deal of attention ${ }^{1-4}$ proving to be of pivotal importance for the synthesis of complex bioactive molecules and natural products ${ }^{5-6}$.

In $2008^{7}$ iEDDA were suggested as possible metal-free click reactions. In the same year, Fox $^{8}$ et al. proposed iEDDA as bioorthogonal ligation reactions for the bioconjugation of proteins. As matter of fact, they can proceed fast and in high yield, in aqueous or cell lysate 
media and are compatible with many functional groups commonly occurring in biological substrates. More recently, ${ }^{9-10}$ iEDDA have also been employed in the synthesis of radioimmunoconjugates and radiolabelled antibodies have been successfully prepared using norbornene-conjugated antibodies as dienophile and radiolabelled tetrazine as diene.

The huge number of reagents employed in iEDDA also includes heteroatom-containing dienes or dienophiles (inverse electron demand hetero-Diels-Alder, iHDA) to form the corresponding heterocyclic cycloadducts, important intermediates in the synthesis of natural and pharmacologically active products. ${ }^{11-13}$

From a mechanistic point of view, extensive kinetic and computational studies on iEDDA have been reported, ${ }^{14-18}$ confirming the involvement of the HOMO orbital of the dienophile and the LUMO orbital of the diene.

In this context, in the last two decades, we successfully developed highly selective iHDA employing $\alpha, \alpha^{\prime}$-dioxothiones as original electron-poor heterodienes (Scheme 1). These latter were aliphatic (1), ${ }^{19}$ aromatic $(\mathbf{2})^{20}$ or saccharidic (3) ${ }^{21-22}$ in addition we also prepared dioxothiones containing an aminoacid fragment $(4) .{ }^{23} \alpha, \alpha^{\prime}$-Dioxothiones are highly reactive species which can be generated in the presence of weak bases, under very mild conditions (room temperature or $40-60{ }^{\circ} \mathrm{C}$ ) and trapped in situ with electron-rich dienophiles to undergo chemo-, regio- and steroselective iHDA to form the corresponding 5,6-dihydro-1,4-oxathiin derivatives 5 .

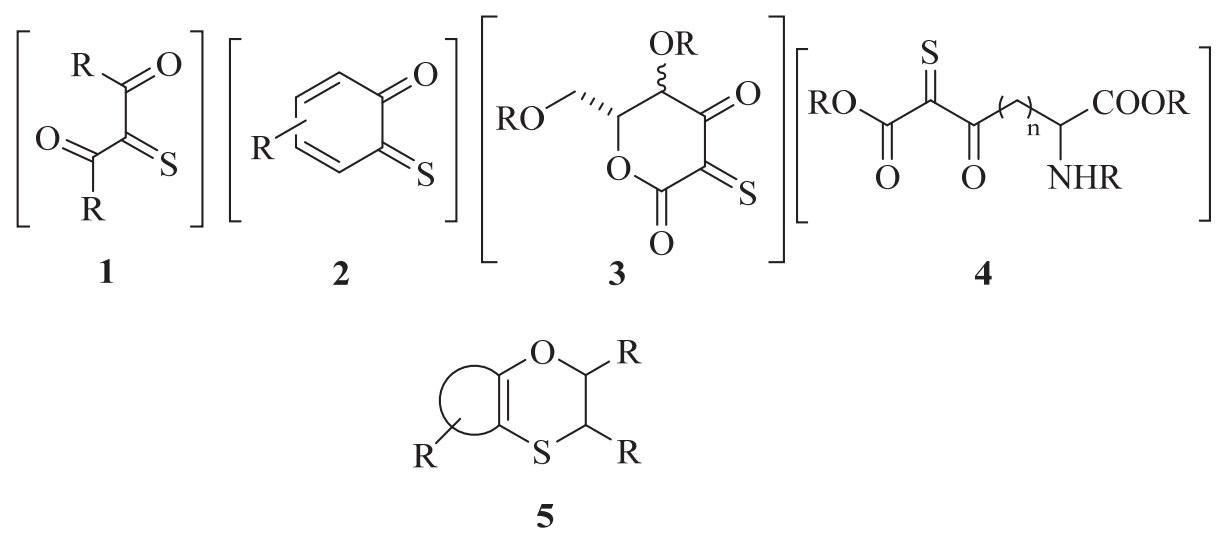

Scheme 1. Structure of $\alpha, \alpha^{\prime}$-oxothiones 1-4 and of oxathiin 5 .

Relying on the stereochemical outcomes of these iHDA, ${ }^{12,24}$ the proper selection of dienes and dienophiles allowed us to obtain an array of synthetically and biologically attracting molecules. In particular, focusing on the use of saccharidic dienophiles, we recently prepared diasteromerically pure glycosyl derivatives of relevant biological interest. ${ }^{25-29}$ As matter of fact, $\alpha, \alpha^{\prime}$-dioxothiones 1a and $\mathbf{4 a}$ were successfully employed in iHDA with exo-glycal $\mathbf{6}^{30}$ and 1galactal 7 to prepare respectively cycloadducts $\mathbf{8}^{30}$ and $9,{ }^{28}$ the first spiro sialyl derivative, the second a mimetic of the mucins $\mathrm{Tn}$ antigen. In addition, the micromolar water soluble matrix metalloproteinases inhibitors $\mathbf{1 0}^{25}$ were formed by iHDA reaction of $\mathrm{D}(+)$ glucal with the thione $\mathbf{4 b}$, obtained from aspartic acid. (Scheme 2). 

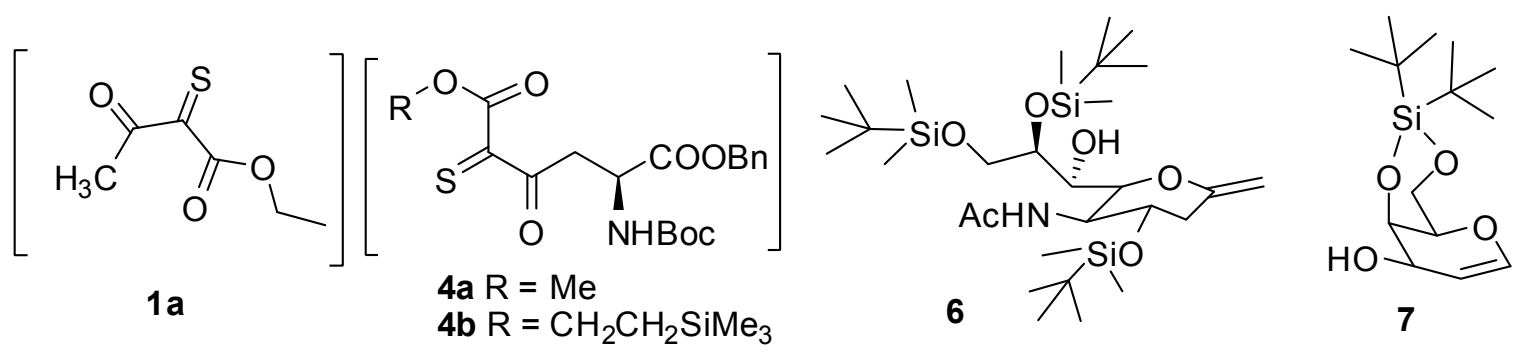

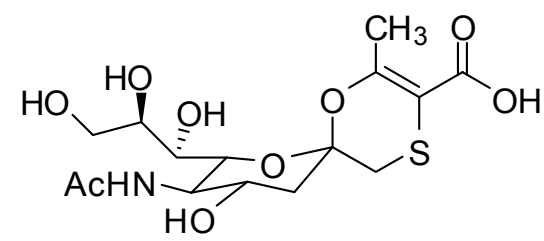

8<smiles>O=C1N[C@@H](C(=O)O)CC2=C1C(=O)N[C@H](CO)C2OCCO</smiles>

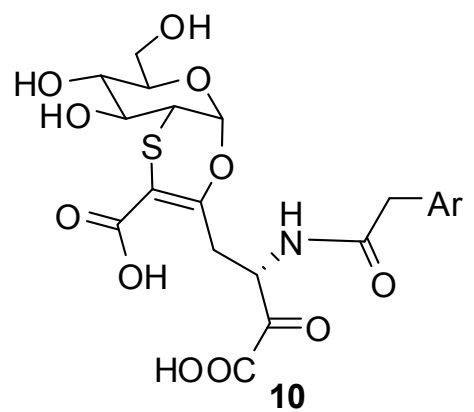

Scheme 2. Structure of electron-poor dienes 1a and 4a-b, electron-rich dienophiles 6 and 7 and of glycosyl derivatives $\mathbf{8 , 9}$ and $\mathbf{1 0}$

We reported herein on the extension of this class of iHDA to KDO-related glycals as electron-rich dienophiles, to prepare the diasteromerically pure KDO-related glycosides $\mathbf{1 1}$ and 12a-c (Scheme 3). The biological activity of $\mathbf{1 1}$ and $\mathbf{1 2 a}$ as sialidase inhibitors was also investigated.

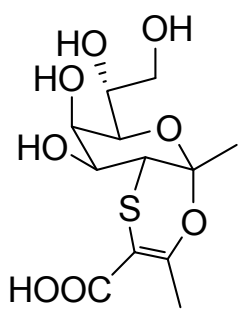

11

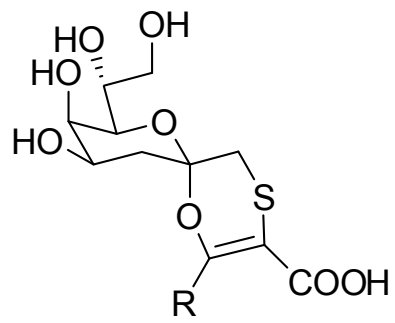

12a $\mathrm{R}=\mathrm{Me}$

12b $\mathrm{R}=p-\mathrm{F}-\mathrm{C}_{6} \mathrm{H}_{4}$

12c $\mathrm{R}=m-\mathrm{MeO}-\mathrm{C}_{6} \mathrm{H}_{4}$

Scheme 3. Structures of the KDO-related glycosides 11 and 12a-c.

\section{Results and Discussion}

Cycloadducts 12a-c were prepared by iHDA reactions employing the KDO-based exo-glycal $\mathbf{1 3}^{31}$ (Scheme 4) as electron-rich dienophile and $\alpha, \alpha^{\prime}$-dioxothiones $\mathbf{1 a - \mathbf { c } ^ { 3 0 }}$ as electron poor dienes. All the reactions were totally chemo- regio- and diasteroselective. The heterodienes 1a-c 
(Scheme 4), in turn, were obtained by the mild base treatment (pyridine, room temperature) of the parent sulfenyl derivatives $\mathbf{1 4 a - c}$, as previously reported. ${ }^{30}$

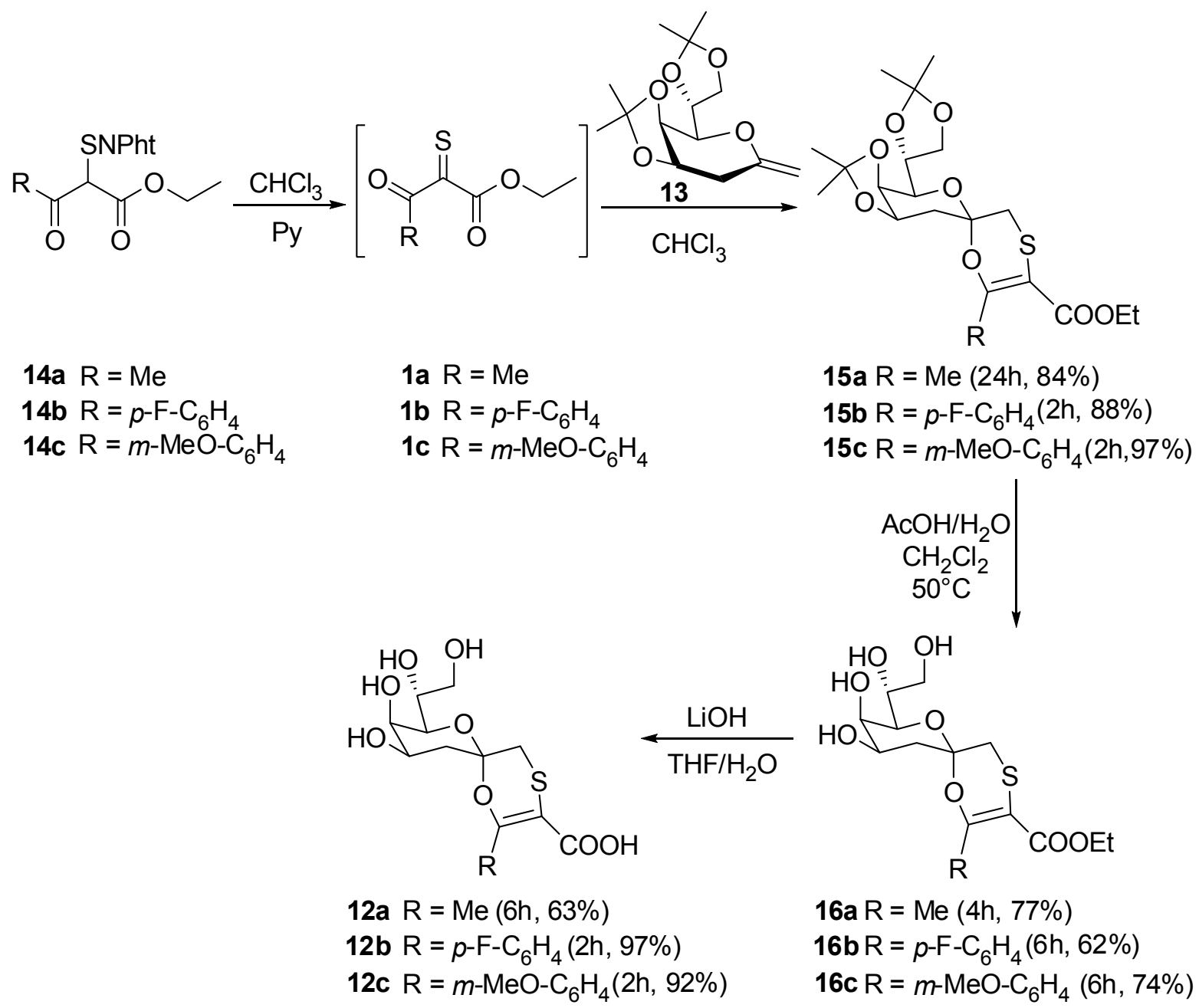

Scheme 4. Synthesis of the cycloadducts 12a-c.

The highly reactive dienes 1a-c were generated in situ in the presence of the dienophile $\mathbf{1 3}$ and afforded the corresponding cycloadducts 15a-c in high yield (84-97\%) (Scheme 4) and as single diasteroisomers. As expected, all cycloadducts (15a-c) were formed as the $\alpha$-isomer, that is the isomer obtained from the preferred attack of the thiones 1a-c to the bottom face of the dienophile 13. ${ }^{24,26} \mathrm{~A}$ matter of fact, all the iHDAs were totally chemo- regio- and stereoselective according with our previous data obtained and reported ${ }^{26}$ employing $\mathbf{1 3}$ as electron-rich dienophile. Hydrolysis of the isopropylidene protecting groups of 15a-c was accomplished in good yield $(62-77 \%, \mathbf{1 6 a - c})$ by treating 15a-c with a $1.5 / 1(\mathrm{v} / \mathrm{v})$ mixture of acetic acid and water at $50^{\circ} \mathrm{C}$. The final deprotection of the carboxylic residues of 16a-c (Scheme 4) with lithium hydroxide $\left(1 \mathrm{M}\right.$ in $\left.\mathrm{H}_{2} \mathrm{O}\right)$ in THF as solvent, provided the desired glycosyl derivatives $\mathbf{1 2 a}-\mathbf{c}$. 
Analogously, the synthesis of the glycosyl derivative 11 was accomplished by an iHDA reaction between the $\alpha, \alpha^{\prime}$-dioxothione 1a and the glycal 17 (Scheme 5).

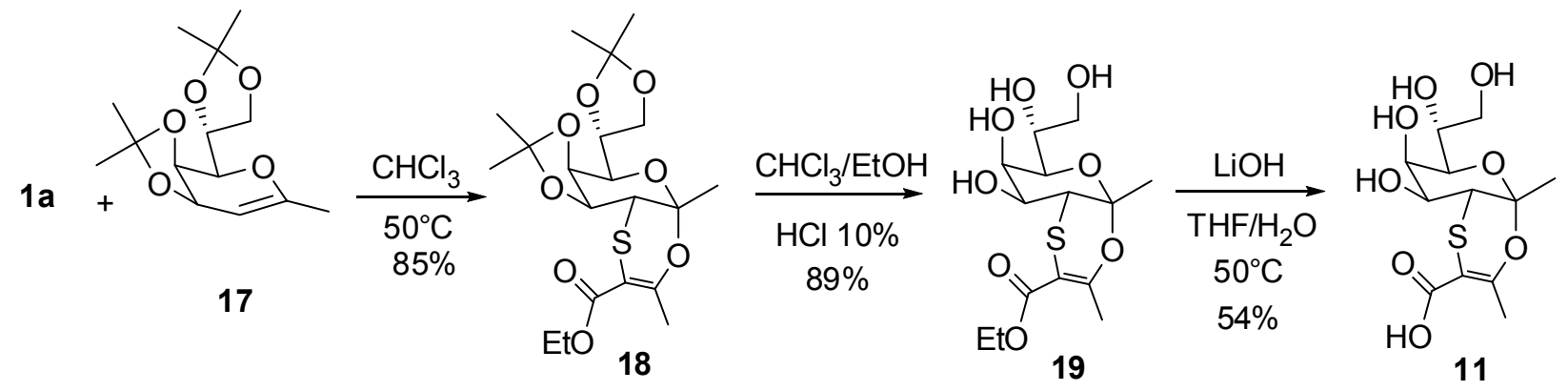

Scheme 5. Synthesis of cycloadduct 11.

Glycal 17 (Scheme 6) was easily prepared by heating the exo-glycal 13 to $60^{\circ} \mathrm{C}$ for $50 \mathrm{~h}$, in a 1.6/1 mixture of $\mathrm{CH}_{2} \mathrm{Cl}_{2}$ /pyridine as solvent.

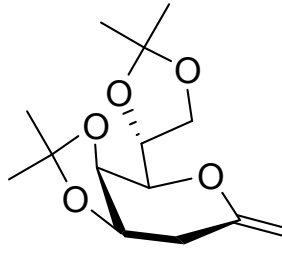

13

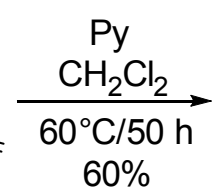

$60 \%$

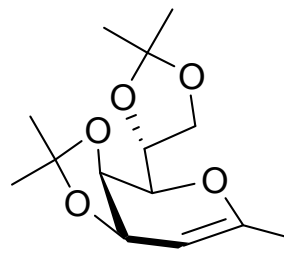

17<smiles>[R]O[C@H]1O[C@H](CO)[C@@H](O)C2=C1SC[C@]1(O2)O[C@H]([C@H](O)CO)[C@@H](O)[C@H](O)[C@H]1O</smiles>

Scheme 6. Synthesis of glycal 17 and structure of the $\mathrm{GM}_{3}$ lactone mimetic, 20.

The iHDA of 1a with 17 (Scheme 5) was performed in a $1 / 2$ mixture of $\mathrm{CHCl}_{3} /$ pyridine at $50^{\circ} \mathrm{C}$ and the cycloadduct 18, was formed as pure $\alpha$ isomer and in high yield (85\%). The analysis of the ${ }^{1} \mathrm{H}$ NMR spectra of $\mathbf{1 8}$ allowed us to ascertain that also in this case, the electron-poor diene (1a) preferentially attacked the lower face of the dienophile (17) affording the thermodynamically more stable $\alpha$-O-glycosyl derivative $\left(J_{3-4} 8.4 \mathrm{~Hz}\right)$. Furthermore, the value of the chemical shift of $\mathrm{H}-3$ (2.78 ppm) confirmed the regioselectivite formation of the $\mathrm{C}_{3}-\mathrm{S}$ linkage. $^{28}$

Hydrolysis of the isopropylidene protecting groups of $\mathbf{1 8}$ with a solution of $\mathrm{HCl}(10 \%$ in $\mathrm{EtOH}$ ), followed by the deprotection of the carboxylic residue of 19 with lithium hydroxide (1M in $\mathrm{H}_{2} \mathrm{O}$ ) in THF as solvent, provided the desired glycosyl derivative 11 (Scheme 5). 
Capitalizing on the biological issues recently reported ${ }^{27}$ for $\mathbf{2 0}$ (see Scheme 6), a tricyclic thio-mimetic of the melanoma antigen $\mathrm{GM}_{3}$ lactone ganglioside, characterized by the replacement of the native sialic acid moiety with a KDO-related residue, and taking into account the structural analogy of KDO-like fragment of compound $\mathbf{2 0}$ with that of derivatives $\mathbf{1 1}$ and 12a-c, we investigated the potential activity of $\mathbf{1 1}$ and 12a as inhibitors of influenza virus sialidase. The sialidase enzyme on influenza virus, recognizing sialic acid and its derivative, plays a major role in the virus life cycle by facilitating the release of virus progeny from the infected cells. ${ }^{32}$

To this end, we measured drug inhibition of the sialidase activity of A/Mississippi/3/2001 wild type H1N1 influenza virus ${ }^{33}$ by the MUNANA based fluorescent assay ${ }^{34}$ as previously described. ${ }^{35}$ Both compounds $\mathbf{1 1}$ and 12a did inhibit the enzyme activity of the H1N1 virus, but compared to zanamivir, the inhibition curves obtained for compounds 11 and 12a showed unusual steep shifts in percent inhibition over a very narrow range. Because of this, a narrower range of dilutions was used to more accurately determine their $\mathrm{IC}_{50} \mathrm{~s},(10,100,300,600,800$, 1000, 3000, 10,000 for compound $\mathbf{1 1}$ and 10, 100, 300, 1000, 2000, 3000, 10,000 for compound 12a).The $\mathrm{IC}_{50}$ s thus assessed were $760 \mu \mathrm{M}$ for compound 11 and $1880 \mu \mathrm{M}$ for 12a, compared to $2.2 \mathrm{nM}$ for zanamivir.

\section{Conclusions}

Herein we reported the extension of a powerful diasteroselective iHDA to the synthesis of KDObased glycosyloxathiins 11 and 12a-c (Scheme 3) efficiently prepared in few steps reacting two KDO-based enitols as electron-rich dienophiles. The data obtained confirmed that this peculiar class of iHDA is an efficient and versatile access to structurally heterogeneous diasteropure constructs.

Keeping in mind the recursively pandemic influenza A infections as well as the reported virus resistance to commonly used drugs like oseltamivir which make the discovery of new antiinfluenza drugs compelling, the sialidase inhibition properties of $\mathbf{1 1}$ and 12a were evaluated. The enzyme inhibition tests were carried out on the A/Mississippi/03/01 H1N1 virus sialidase, showing that both compounds, 11 and 12a, inhibited the enzyme activity. In particular, compound 11 was about 2 -fold more effective than 12a. The striking steep inhibition curves obtained likely reflect a difference in the binding interactions of $\mathbf{1 1}$ and 12a vs. the influenza NA active site with respect to zanamivir. In conclusion, though sensibly less effective than the golden standard zanamivir, the KDO-related glycosyloxathiin 11 inhibits sialidase and is characterized by an original and multifunctional scaffold helpful to develop a new generation of drugs. Structural modifications and further binding profile investigations are underway. 


\section{Experimental Section}

General. All solvents were of reagent grade quality and purchased commercially. All starting materials were purchased commercially and used without further purification. All NMR spectra were recorded on Varian instruments (200 or $300 \mathrm{MHz}$ ) and Mercury 400 instruments. The NMR spectra were referenced to solvent. Mass spectra were recorded on a LCQ-FLEET ion trap Thermo Fisher. ESI-MS analysis was performed both in positive or negative/ion mode. HRMS were performed on a LTQ-IT-Orbitrap with a spray voltage of $2.10 \mathrm{kV}$ and a resolution of 100,000 . Optical rotation measurements were carried out with a Jasco DIP-370 polarimeter.

Elementary analysis experiments of purified products were performed with an Elementary Analyzer 2400 Serie II Perkin-Elmer. Complete signal assignments from 1D and 2D NMR were based on COSY, HSQC correlations. The A/Mississippi/3/2001 wild type H1N1 influenza virus $^{34}$ was used to evaluate susceptibility in the enzyme inhibition assays. Zanamivir was provided by GlaxoSmithKline (Stevenage, UK)

Synthesis of compound 15a. To a solution of $13^{31}(0.168 \mathrm{~g}, 0.617 \mathrm{mmol})$ in dry pyridine $(4.0$ $\mathrm{mL}), \mathbf{1 4 a}^{30}(0.208 \mathrm{mg}, 0.68 \mathrm{mmol})$ was added. The mixture was warmed to $40^{\circ} \mathrm{C}$ and stirred for $6 \mathrm{~h}$. After this time 14a $(0.208 \mathrm{mg}, 0.68 \mathrm{mmol})$ was added and the mixture was stirred at $40^{\circ} \mathrm{C}$ for $18 \mathrm{~h}$. The reaction mixture was cooled to rt, diluted with $\mathrm{CH}_{2} \mathrm{Cl}_{2}(50 \mathrm{~mL})$ and washed with a saturated solution of $\mathrm{NH}_{4} \mathrm{Cl}(2 \times 10 \mathrm{~mL})$. The organic phase was dried over $\mathrm{Na}_{2} \mathrm{SO}_{4}$ and concentrated to dryness to give a crude which was purified by flash column chromatography on silica gel (AcOEt:Petroleum Ether, 1:6) to give 15a $(0.222 \mathrm{~g}, 84 \%)$ as a yellow oil. $[\alpha]_{25}{ }^{\mathrm{D}}+5.9$ (c $\left.0.44, \mathrm{CH}_{2} \mathrm{Cl}_{2}\right) ;{ }^{1} \mathrm{H}$ NMR $\left(400 \mathrm{MHz}, \mathrm{CDCl}_{3}\right): \delta 4.58\left(\mathrm{dt}, J_{3-2 a}=J_{3-2 b} 7.6 \mathrm{~Hz}, J_{3-4} 3.2 \mathrm{~Hz}, 1 \mathrm{H}, \mathrm{H}-\right.$ 3), 4.35 (dd, $\left.J_{4-3} 7.6 \mathrm{~Hz}, J_{4-5} 2.0 \mathrm{~Hz}, 1 \mathrm{H}, \mathrm{H}-4\right), 4.29-4.24(\mathrm{~m}, 1 \mathrm{H}, \mathrm{H}-6), 4.19$ (q, $J 7.2 \mathrm{~Hz}, 2 \mathrm{H}$, $\mathrm{CH}_{2} \mathrm{CH}_{3}$ ), 4.06-4.03 (A part of an ABX system, $J_{A B} 9.2 \mathrm{~Hz}, J_{A X} 6.4 \mathrm{~Hz}, 1 \mathrm{H}, \mathrm{H}-7 \mathrm{a}$ ), 3.85-3.81 (B part of an ABX system, $\left.J_{B A} 8.8 \mathrm{~Hz}, J_{B X} 4.4 \mathrm{~Hz}, 1 \mathrm{H}, \mathrm{H}-7 \mathrm{~b}\right), 3.66$ (dd, $J_{5-6} 7.6 \mathrm{~Hz}, J_{5-4} 1.6 \mathrm{~Hz}$, $1 \mathrm{H}, \mathrm{H}-5$ ), 3.07-3.04 (A part of an AB system, $J_{A B} 12.8 \mathrm{~Hz}, \mathrm{H}-1^{\prime} \mathrm{a}$ ), 2.82-2.79 (B part of an AB system, $J_{B A} 12.8 \mathrm{~Hz}, 1 \mathrm{H}, \mathrm{H}-1$ 'b), 2.45-2.40 (A part of an ABX system, $J_{A B} 15.6 \mathrm{~Hz}, J_{A X} 3.2 \mathrm{~Hz}$, $1 \mathrm{H}, \mathrm{H}-2 \mathrm{a}$ ), 2.29 (s, 3H, $\mathrm{CH}_{3} \mathrm{C}=$ ), 2.00-1.95 (B part of an ABX system, $J_{B A} 15.6 \mathrm{~Hz}, J_{B X} 3.2 \mathrm{~Hz}$, $1 \mathrm{H}, \mathrm{H}-2 \mathrm{~b}), 1.44$ (s, 3H, $\left.\left(\mathrm{CH}_{3}\right)_{2} \mathrm{C}\right), 1.39\left(\mathrm{~s}, 3 \mathrm{H},\left(\mathrm{CH}_{3}\right)_{2} \mathrm{C}\right), 1.34$ (s, 6H, $\left.\left(\mathrm{CH}_{3}\right)_{2} \mathrm{C}\right), 1.29$ (t, J 6.8 $\left.\mathrm{Hz}, 3 \mathrm{H}, \mathrm{CH}_{2} \mathrm{CH}_{3}\right) ;{ }^{13} \mathrm{C}$ NMR $\left(100 \mathrm{MHz}, \mathrm{CDCl}_{3}\right): \delta 164.9,157.3,109.3,109.2,97.7,94.8,73.3$, 72.0, 70.5, 66.9, 60.8, 34.6, 34.0, 26.8, 26.2, 25.2, 25.0, 21.7, 14.3; ESI-MS: $m / z 453.17$ [M + $\mathrm{Na}]^{+}$; Anal. Calcd for $\mathrm{C}_{20} \mathrm{H}_{30} \mathrm{O}_{8} \mathrm{~S}$ (430.16): C, 55.80; H, 7.02\%. Found: C, 55.82; H, 7.06\%.

Synthesis of compound 16a. To a stirred solution of 15a $(0.102 \mathrm{~g}, 0.237 \mathrm{mmol})$ in glacial $\mathrm{AcOH}(3.5 \mathrm{~mL}), \mathrm{H}_{2} \mathrm{O}(1.5 \mathrm{~mL})$ was slowly added. The reaction mixture was warmed to $50^{\circ} \mathrm{C}$ and stirred for $4 \mathrm{~h}$. After this time, the solvent was co-evaporated with toluene under reduced pressure to give a crude which was purified by flash column chromatography on silica gel (AcOEt:MeOH, 10:1) to give 16a $(0.064 \mathrm{~g}, 77 \%)$ as a white solid. $[\alpha]_{25}{ }^{\mathrm{D}}+94.6$ (c 0.465 , $\mathrm{MeOH}$ ); mp: $134-136^{\circ} \mathrm{C}$; ${ }^{1} \mathrm{H}$ NMR (400MHz, $\left.\mathrm{CD}_{3} \mathrm{OD}\right): \delta 4.25-4.17$ (m, $2 \mathrm{H}, \mathrm{CH}_{2} \mathrm{CH}_{3}$ ), 4.12-4.06 (m, 2H, H-3, H-4), 3.92-3.87 (m, 1H, H-6), 3.77-3.73 (A part of an ABX system, $J_{A B} 11.6 \mathrm{~Hz}$, $\left.J_{A X} 4.0 \mathrm{~Hz}, 1 \mathrm{H}, \mathrm{H}-7 \mathrm{a}\right), 3.58$ (d, $\left.J_{5-6} 8.8 \mathrm{~Hz}, J_{5-4} 0.8 \mathrm{~Hz}, 1 \mathrm{H}, \mathrm{H}-5\right), 3.46-3.42$ (B part of an ABX 
system, $J_{B A} 11.6 \mathrm{~Hz}, J_{B X} 6.4 \mathrm{~Hz}, 1 \mathrm{H}, \mathrm{H}-7 \mathrm{~b}$ ), 2.93-2.90 (A part of an AB system, $J_{A B} 13.2 \mathrm{~Hz}$, $1 \mathrm{H}, \mathrm{H}-1^{\prime} \mathrm{a}$ ), 2.89-2.86 (B part of an AB system, $J_{B A} 13.2 \mathrm{~Hz}, 1 \mathrm{H}, \mathrm{H}-1^{\prime} \mathrm{b}$ ), 2.33 (s, 3H, $\mathrm{CH}_{3} \mathrm{C}=$ ), 1.98-1.92 (m, 2H, H-1'a, H-1'b), 1.31 (t, $\left.J 7.2 \mathrm{~Hz}, 3 \mathrm{H}, \mathrm{CH}_{2} \mathrm{CH}_{3}\right) ;{ }^{13} \mathrm{C}$ NMR (100MHz, CD $\left.{ }_{3} \mathrm{OD}\right)$ : $\delta 166.7(\mathrm{Cq}), 157.6(\mathrm{Cq}), 99.4(\mathrm{Cq}), 96.2(\mathrm{Cq}), 74.9(\mathrm{C}-5), 70.2(\mathrm{C}-6), 67.6(\mathrm{C}-4), 67.3 \mathrm{C}-3)$, $65.5(\mathrm{C}-7), 61.9\left(\mathrm{CH}_{2} \mathrm{CH}_{3}\right), 37.1(\mathrm{C}-2), 33.7\left(\mathrm{C}-1^{\prime}\right), 21.4\left(\mathrm{CH}_{3} \mathrm{C}=\right), 14.5\left(\mathrm{CH}_{2} \mathrm{CH}_{3}\right)$; ESI-MS: $m / z$ $373.18[\mathrm{M}+\mathrm{Na}]^{+}$, $389.09[\mathrm{M}+\mathrm{K}]^{+}$; Anal. Calcd for $\mathrm{C}_{14} \mathrm{H}_{22} \mathrm{O}_{8} \mathrm{~S}$ (350.10): C, 47.99; H, 6.33\%. Found: C, 47.97; H, 6.29\%.

Synthesis of compound 12a. To a stirred solution of 16a $(0.200 \mathrm{~g}, 0.571 \mathrm{mmol})$ in THF (14.0 $\mathrm{mL}), 3.42 \mathrm{~mL}$ of $1 \mathrm{M}$ solution of $\mathrm{LiOH}(3.42 \mathrm{mmol})$ in $\mathrm{H}_{2} \mathrm{O}$ were added. The reaction mixture was warmed at $50^{\circ} \mathrm{C}$ for $6 \mathrm{~h}$ then $1 \mathrm{M}$ solution of $\mathrm{H}_{3} \mathrm{PO}_{4}$ was added to reach $\mathrm{pH} 5$. The solvent was co-evaporated with toluene under reduced pressure to give a crude which was suspended in dry $\mathrm{MeOH}$ and filtered through a PTFE membrane (pore size $0.20 \mathrm{uM}$ ). The filtrate was concentrated to dryness and purified by HPLC (column Zorbax RX-Silica, 9.4x250, 5 um, AcOEt:MeOH 90:10 to 50:50) to give 12a $(0.116 \mathrm{~g}, 63 \%)$ as an oil. $[\alpha]_{25}{ }^{\mathrm{D}}+55.2$ (c 0.30 , $\mathrm{MeOH}$ ); ${ }^{1} \mathrm{H}$ NMR (400MHz, $\mathrm{CD}_{3} \mathrm{OD}$ ): $\delta$ 4.10-4.04 (m, 2H, H-3, H-4), 3.89-3.84 (m, 1H, H-6), 3.76-3.72 (A part of an ABX system, $\left.J_{A B} 11.6 \mathrm{~Hz}, J_{A X} 3.6 \mathrm{~Hz}, 1 \mathrm{H}, \mathrm{H}-7 \mathrm{a}\right), 3.55-3.53$ (m, $1 \mathrm{H}, \mathrm{H}-$ 5), 3.44-3.40 (B part of an ABX system, $J_{B A} 11.6 \mathrm{~Hz}, J_{B X} 6.8 \mathrm{~Hz}, 1 \mathrm{H}, \mathrm{H}-7 \mathrm{~b}$ ), 2.90-2.87 (A part of an $\mathrm{AB}$ system, $J_{A B} 13.2 \mathrm{~Hz}, 1 \mathrm{H}, \mathrm{H}-1^{\prime} \mathrm{a}$ ), 2.86-2.82 (B part of an AB system, $J_{B A} 13.2 \mathrm{~Hz}, 1 \mathrm{H}$, $\mathrm{H}-1$ 'b), 2.3 (s, $3 \mathrm{H}, \mathrm{CH}_{3} \mathrm{C}=$ ), $1.95-1.92$ (m, $\left.2 \mathrm{H}, \mathrm{H}-2 \mathrm{a}, \mathrm{H}-2 \mathrm{~b}\right) ;{ }^{13} \mathrm{C}$ NMR $\left(50 \mathrm{MHz}, \mathrm{CD}_{3} \mathrm{OD}\right): \delta$ 168.4, 157.3, 99.8, 96.0, 74.9, 70.2, 67.5, 67.3, 65.6, 37.2, 33.8, 21.4; HRMS: $\mathrm{m} / \mathrm{z}$ calcd for $\mathrm{C}_{12} \mathrm{H}_{17} \mathrm{O}_{8} \mathrm{~S}[\mathrm{M}-\mathrm{H}]^{-} 321.06496$, found 321.06476.

Synthesis of compound 17. To a stirred solution of $\mathbf{1 3}(0.500 \mathrm{~g}, 1.85 \mathrm{mmol})$ in $\mathrm{CH}_{2} \mathrm{Cl}_{2}(8.0$ $\mathrm{mL})$, dry pyridine $(5.0 \mathrm{~mL})$ was added. The mixture was warmed at $60^{\circ} \mathrm{C}$ for $50 \mathrm{~h}$ then diluted with $\mathrm{CH}_{2} \mathrm{Cl}_{2}(80 \mathrm{~mL})$ and washed with a saturated solution of $\mathrm{NH}_{4} \mathrm{Cl}(2 \times 10 \mathrm{~mL})$. The organic phase was dried over $\mathrm{Na}_{2} \mathrm{SO}_{4}$ and concentrated to dryness to give a crude which was purified by flash column chromatography on silica gel (AcOEt:Petroleum Ether $+\mathrm{NEt}_{3} 0.1 \%, 1: 8$ ) to give 17 $(0.300 \mathrm{~g}, 60 \%)$ as a yellow oil. $[\alpha]_{25}{ }^{\mathrm{D}}+34.5\left(c 0.44, \mathrm{CH}_{2} \mathrm{Cl}_{2}\right) ;{ }^{1} \mathrm{H}$ NMR $\left(400 \mathrm{MHz}, \mathrm{CDCl}_{3}\right): \delta$ 4.66-4.64 (m, 1H), 4.40-4.36 (m, 2H), 4.14-4.07 (m, 2H), 3.71 (dd, J $1.2 \mathrm{~Hz}, J 8.0 \mathrm{~Hz}, 1 \mathrm{H})$, $1.73(\mathrm{~s}, 3 \mathrm{H}), 1.43$ (s, 3H), 1.42 (s, 3H), $1.38(\mathrm{~s}, 3 \mathrm{H}), 1.37$ (s, 3H); ${ }^{13} \mathrm{C}$ NMR $\left(100 \mathrm{MHz}, \mathrm{CDCl}_{3}\right): \delta$ 152.7, 110.1, 109.4, 75.6, 74.1, 71.4, 69.6, 66.7, 28.0, 26.9, 26.8, 25.3, 19.6; ESI-MS: $m / z 293.17$ $[\mathrm{M}+\mathrm{Na}]^{+}$; Anal. Calcd for $\mathrm{C}_{14} \mathrm{H}_{22} \mathrm{O}_{5}(270.14): \mathrm{C}, 62.20 ; \mathrm{H}, 8.20 \%$. Found: $\mathrm{C}, 62.18 ; \mathrm{H}, 8.24 \%$.

Synthesis of compound 18. To a solution of $17(0.300 \mathrm{~g}, 1.11 \mathrm{mmol})$ in $\mathrm{CHCl}_{3}(2.5 \mathrm{~mL})$ dry pyridine $(5.5 \mathrm{~mL})$ and $14 \mathrm{a}(0.441 \mathrm{mg}, 1.435 \mathrm{mmol})$ were added. The mixture was warmed at $50^{\circ} \mathrm{C}$ and stirred for $6 \mathrm{~h}$. After this time 14a $(0.441 \mathrm{mg}, 1.435 \mathrm{mmol})$ was added and the mixture was stirred at $50^{\circ} \mathrm{C}$ for $18 \mathrm{~h}$. The reaction mixture was cooled at rt, diluted with $\mathrm{CH}_{2} \mathrm{Cl}_{2}(70 \mathrm{~mL})$ and washed with a saturated solution of $\mathrm{NH}_{4} \mathrm{Cl}(2 \times 15 \mathrm{~mL})$. The organic phase was dried over $\mathrm{Na}_{2} \mathrm{SO}_{4}$ and concentrated to dryness to give a crude which was purified by flash column chromatography on silica gel (AcOEt:Petroleum Ether $\left.+\mathrm{NEt}_{3} 0.1 \%, 1: 7\right)$ to give $\mathbf{1 8}(0.406 \mathrm{~g}$, $85 \%)$ as a white solid. $[\alpha]_{25}{ }^{\mathrm{D}}+96.8\left(\mathrm{c} 0.22, \mathrm{CH}_{2} \mathrm{Cl}_{2}\right)$; mp: $104-106{ }^{\circ} \mathrm{C} ;{ }^{1} \mathrm{H}$ NMR $(400 \mathrm{MHz}$, $\mathrm{C}_{6} \mathrm{D}_{6}$ ): $\delta{ }^{1} \mathrm{H}$ NMR $\left(400 \mathrm{MHz}, \mathrm{C}_{6} \mathrm{D}_{6}\right.$ ): $\delta$ 4.48-4.43 (m, 1H, H-7), 4.14-4.11 (A part of an ABX 
system, $J_{A B} 8.4 \mathrm{~Hz}, J_{A X} 5.2 \mathrm{~Hz}, 1 \mathrm{H}, \mathrm{H}-8 \mathrm{a}$ ), 4.11-4.08 (B part of an ABX system, $J_{B A} 7.6 \mathrm{~Hz}, J_{B X}$ $2.4 \mathrm{~Hz}, 1 \mathrm{H}, \mathrm{H}-8 \mathrm{~b}$ ), 4.063-3.93 (m, 4H, H-5, H-6, $\mathrm{CH}_{2} \mathrm{CH}_{3}$ ), 3.80 (dd, $J_{4-3} 8.4 \mathrm{~Hz}, J_{4-5} 4.8 \mathrm{~Hz}$, $1 \mathrm{H}, \mathrm{H}-4), 2.78$ (d, $\left.J_{3-4} 8.4 \mathrm{~Hz}, 1 \mathrm{H}, \mathrm{H}-3\right), 2.33$ (s, 3H, CH $\left.\mathrm{C}_{3} \mathrm{C}\right), 1.46$ (s, 3H, H-1), 1.37 (s, 3H, $\left.\left(\mathrm{CH}_{3}\right)_{2} \mathrm{C}\right), 1.29\left(\mathrm{~s}, 3 \mathrm{H},\left(\mathrm{CH}_{3}\right)_{2} \mathrm{C}\right), 1.22\left(\mathrm{~s}, 3 \mathrm{H},\left(\mathrm{CH}_{3}\right)_{2} \mathrm{C}\right), 1.17\left(\mathrm{~s}, 3 \mathrm{H},\left(\mathrm{CH}_{3}\right)_{2} \mathrm{C}\right), 0.94(\mathrm{t}, \mathrm{J} 7.2 \mathrm{~Hz}$, $\left.3 \mathrm{H}, \mathrm{CH}_{2} \mathrm{CH}_{3}\right) ;{ }^{13} \mathrm{C} \mathrm{NMR}\left(50 \mathrm{MHz}, \mathrm{C}_{6} \mathrm{D}_{6}\right): \delta 164.5,158.5,108.8,108.7,98.6,93.8,73.9,73.6$, 72.0, 69.8, 66.7, 60.3, 43.7, 27.9, 26.4, 25.8, 24.9, 20.8, 13.6; ; ESI-MS: $m / z 453.17[\mathrm{M}+\mathrm{Na}]^{+}$; Anal. Calcd for $\mathrm{C}_{20} \mathrm{H}_{30} \mathrm{O}_{8} \mathrm{~S}$ (430.16): C, 55.80; H, 7.02\%. Found: C, 55.88; H, 7.00\%.

Synthesis of compound 19. To a solution of $18(0.434 \mathrm{~g}, 1.00 \mathrm{mmol})$ in $\mathrm{CHCl}_{3}: \mathrm{EtOH} / 1: 2(15.0$ $\mathrm{mL}), 2.0 \mathrm{~mL}$ of $\mathrm{HCl}$ solution $(10 \%$ in $\mathrm{EtOH})$ were added. The reaction mixture was stirred overnight at $\mathrm{rt}$ then neutralized with $\mathrm{NEt}_{3}$ and the solvent removed under reduced pressure. The crude was purified by flash chromatography on silica gel (AcOEt:MeOH 12:1) to give 19 (0.310 g, 89\%) as a glassy solid. $[\alpha]_{25}{ }^{\mathrm{D}}+146.0(c 0.370, \mathrm{MeOH}) ;{ }^{1} \mathrm{H}$ NMR $\left(400 \mathrm{MHz}, \mathrm{CD}_{3} \mathrm{OD}\right): \delta 4.21-$ $4.13\left(\mathrm{~m}, 2 \mathrm{H}, \mathrm{CH}_{2} \mathrm{CH}_{3}\right), 4.05$ (dd, $\left.J_{5-6} 2.8 \mathrm{~Hz}, J_{5-4} 0.8 \mathrm{~Hz}, 1 \mathrm{H}, \mathrm{H}-5\right), 3.88-3.84$ (m, 1H, H-7), 3.80-3.75 (m, 2H, H-6, H-8a), 3.58-3.53 (B part of an ABX system, $J_{B A} 11.6 \mathrm{~Hz}, 6.4 \mathrm{~Hz}, 1 \mathrm{H}, \mathrm{H}-$ 8b), 3.43 (dd, $\left.J_{4-3} 10.4 \mathrm{~Hz}, J_{4-5} 3.2 \mathrm{~Hz}, 1 \mathrm{H}, \mathrm{H}-4\right), 3.11$ (d, $\left.J_{3-4} 10.4 \mathrm{~Hz}, 1 \mathrm{H}, \mathrm{H}-3\right), 2.3$ (s, 3H, $\mathrm{CH}_{3} \mathrm{C}=$ ), 1.59 (s, 3H, H-1), 1.27 (t, $\left.J 7.2 \mathrm{~Hz}, 3 \mathrm{H}, \mathrm{CH}_{2} \mathrm{CH}_{3}\right) ;{ }^{13} \mathrm{C}$ NMR (100MHz, CD $\left.{ }_{3} \mathrm{OD}\right): \delta$ 167.1, 160.3, 101.4, 94.4, 73.3 (C-6), 71.0 (C-7), 69.0 (C-5), 68.5 (C-4), 64.6 (C-8), 61.9 $\left(\mathrm{CH}_{2} \mathrm{CH}_{3}\right), 44.3(\mathrm{C}-3), 26.7\left(\mathrm{CH}_{3} \mathrm{C}=\right), 21.5(\mathrm{C}-1), 14.5\left(\mathrm{CH}_{2} \mathrm{CH}_{3}\right)$; ESI-MS: $m / z 373.18[\mathrm{M}+$ $\mathrm{Na}]^{+}, 389.09[\mathrm{M}+\mathrm{K}]^{+}$; Anal. Calcd for $\mathrm{C}_{14} \mathrm{H}_{22} \mathrm{O}_{8} \mathrm{~S}$ (350.10): C, 47.99; H, 6.33\%. Found: C, 48.02; H, 6.30\%.

Synthesis of compound 11. To a stirred solution of $19(0.300 \mathrm{~g}, 0.856 \mathrm{mmol})$ in THF $(21.0 \mathrm{~mL})$, $5.13 \mathrm{~mL}$ of $1 \mathrm{M}$ solution of $\mathrm{LiOH}(5.13 \mathrm{mmol})$ in $\mathrm{H}_{2} \mathrm{O}$ were added. The reaction mixture was warmed at $50^{\circ} \mathrm{C}$ for $5 \mathrm{~h}$ then $1 \mathrm{M}$ solution of $\mathrm{H}_{3} \mathrm{PO}_{4}$ was added to reach $\mathrm{pH} 5$. The solvent was co-evaporated with toluene under reduced pressure to give a crude which was suspended in AcOEt:MeOH 1:1 and filtered through a PTFE membrane (pore size 0.20 uM). The filtrate was concentrated to dryness and purified by HPLC (column Zorbax RX-Silica, 9.4x250, 5 um, AcOEt:MeOH 90:10 to 50:50) to give $11(0.150 \mathrm{~g}, 54 \%)$ as a glassy solid. $[\alpha]_{25}{ }^{\mathrm{D}}+90.7$ (c 0.625 , $\mathrm{MeOH}) ;{ }^{1} \mathrm{H}$ NMR (400MHz, $\mathrm{CD}_{3} \mathrm{OD}$ ): $\delta$ 4.09-4.084 (m, 1H, H-5), 3.88-3.84 (m, 1H, H-7), 3.803.77 (m, 2H, H-6, H-8a), 3.58-3.54 (B part of an ABX system, $J_{B A} 11.2 \mathrm{~Hz}, J_{B X} 6.0 \mathrm{~Hz}, 1 \mathrm{H}, \mathrm{H}-$ 8b), 3.49 (dd, $\left.J_{4-3} 10.8 \mathrm{~Hz}, J_{4-5} 3.2 \mathrm{~Hz}, 1 \mathrm{H}, \mathrm{H}-4\right), 3.03$ (d, $J_{3-4} 10.8 \mathrm{~Hz}, 1 \mathrm{H}, \mathrm{H}-3$ ), 2.21 (s, 3H, $\mathrm{CH}_{3} \mathrm{C}=$ ), 1.56 (s, 3H, H-1); ${ }^{13} \mathrm{C}$ NMR (50MHz, $\left.\mathrm{CD}_{3} \mathrm{OD}\right): \delta 173.6,152.8,100.3,99.8,73.1$ (C-6), 71.1 (C-7), 69.0 (C-5), 68.3 (C-4), 64.6 (C-8), 44.5 (C-3), 26.8 (C-1), $20.6\left(\mathrm{CH}_{3} \mathrm{C}=\right)$; ESI-MS: $m / z 321.09$ [M - H] '; HRMS: $m / z$ calcd for $\mathrm{C}_{12} \mathrm{H}_{17} \mathrm{O}_{8} \mathrm{~S}[\mathrm{M}-\mathrm{H}]^{-} 321.06496$, found 321.06484 .

Synthesis of compound $\mathbf{1 5 b}$. To a solution of $13(0.120 \mathrm{~g}, 0.444 \mathrm{mmol})$ in $\mathrm{CHCl}_{3}(1.5 \mathrm{~mL})$ dry pyridine $(2.2 \mathrm{~mL})$ and $\mathbf{1 4} \mathbf{b}^{30}(0.220 \mathrm{mg}, 0.288 \mathrm{mmol})$ were added. The mixture was warmed at $50^{\circ} \mathrm{C}$ and stirred for $1 \mathrm{~h}$. After this time, $14 \mathrm{~b}(0.220 \mathrm{mg}, 0.288 \mathrm{mmol})$ was added and the mixture was stirred at $50^{\circ} \mathrm{C}$ for $1 \mathrm{~h}$. The reaction mixture was cooled at rt, diluted with $\mathrm{CH}_{2} \mathrm{Cl}_{2}(50 \mathrm{~mL})$ and washed with a saturated solution of $\mathrm{NH}_{4} \mathrm{Cl}(2 \times 10 \mathrm{~mL})$. The organic phase was dried over $\mathrm{Na}_{2} \mathrm{SO}_{4}$ and concentrated to dryness to give a crude which was purified by flash column chromatography on silica gel (AcOEt:Petroleum Ether $1: 6)$ to give $\mathbf{1 5 b}(0.200 \mathrm{~g}, 88 \%)$ as a 
glassy solid. $[\alpha]_{25}{ }^{\mathrm{D}}-4.7\left(\mathrm{c} 0.65, \mathrm{CH}_{2} \mathrm{Cl}_{2}\right) ;{ }^{1} \mathrm{H}$ NMR $\left(400 \mathrm{MHz}, \mathrm{CDCl}_{3}\right): \delta$ 7.32-7.26 (m, 2H, $p$-F$\left.\mathrm{C}_{6} \mathrm{H}_{4}\right), 7.05-7.00\left(\mathrm{~m}, 2 \mathrm{H}, p-\mathrm{F}-\mathrm{C}_{6} \mathrm{H}_{4}\right), 4.65-4.61(\mathrm{~m}, 1 \mathrm{H}, \mathrm{H}-3), 4.38$ (dd, $J_{4-3} 8.0 \mathrm{~Hz}, J_{4-5} 2.0 \mathrm{~Hz}$, $1 \mathrm{H}, \mathrm{H}-4$ ), 4.33 (aq, $J 6.4 \mathrm{~Hz}, 1 \mathrm{H}, \mathrm{H}-6$ ), 4.08-4.04 (A part pf an ABX system, $J_{A B} 8.8 \mathrm{~Hz}, J_{A X}$ $6.0 \mathrm{~Hz}, 1 \mathrm{H}, \mathrm{H}-7 \mathrm{a}$ ), 4.02-3.95 (m, 3H, H-7b, $\mathrm{CH}_{2} \mathrm{CH}_{3}$ ), 3.83 (dd, $J_{5-6} 6.8 \mathrm{~Hz}, J_{5-4} 2.0 \mathrm{~Hz}, 1 \mathrm{H}, \mathrm{H}-$ 5), 3.30-3.26 (A part of an AB system, $J_{A B} 12.8 \mathrm{~Hz}, 1 \mathrm{H}, \mathrm{H}-1$ 'a), 2.97-2.93 (B part of an AB system, $J_{B A} 13.2 \mathrm{~Hz}, 1 \mathrm{H}, \mathrm{H}-2 \mathrm{~b}$ ), 2.44-2.39 (A part of an ABX system, $J_{A B} 15.6 \mathrm{~Hz}, J_{A X} 3.2 \mathrm{~Hz}$, 1H, H-1'a), 2.13-2.08 (B part of an ABX system, $J_{B A} 16.0 \mathrm{~Hz}, J_{B X} 3.2 \mathrm{~Hz}, 1 \mathrm{H}, \mathrm{H}-2 \mathrm{~b}$ ), 1.47 (s, $\left.3 \mathrm{H},\left(\mathrm{CH}_{3}\right)_{2} \mathrm{C}\right), 1.39\left(\mathrm{~s}, 3 \mathrm{H},\left(\mathrm{CH}_{3}\right)_{2} \mathrm{C}\right), 1.36\left(\mathrm{~s}, 3 \mathrm{H},\left(\mathrm{CH}_{3}\right)_{2} \mathrm{C}\right), 1.35\left(\mathrm{~s}, 3 \mathrm{H},\left(\mathrm{CH}_{3}\right)_{2} \mathrm{C}\right), 1.01(\mathrm{t}, \mathrm{J} 7.2$ $\left.\mathrm{Hz}, 3 \mathrm{H}, \mathrm{CH}_{2} \mathrm{CH}_{3}\right) ;{ }^{13} \mathrm{C}$ NMR $\left(100 \mathrm{MHz}, \mathrm{CDCl}_{3}\right): \delta 164.9(\mathrm{Cq}), 162.99$ (d, $J 247.8 \mathrm{~Hz}, p$-F$\left.\mathrm{C}_{6} \mathrm{H}_{4}\right), 154.5(\mathrm{Cq}), 134.2(\mathrm{Cq}), 133.4\left(\mathrm{~d}, J 3.8 \mathrm{~Hz}, p-\mathrm{F}-\mathrm{C}_{6} \mathrm{H}_{4}\right), 130.5$ (d, $J$ 8.4 Hz, $p$-F- $\left.\mathrm{C}_{6} \mathrm{H}_{4}\right)$, 123.5, $114.8\left(\mathrm{~d}, J 22.1 \mathrm{~Hz}, p-\mathrm{F}-\mathrm{C}_{6} \mathrm{H}_{4}\right), 109.5(\mathrm{Cq}), 109.2(\mathrm{Cq}), 102.2(\mathrm{Cq}), 94.4(\mathrm{Cq}), 73.8(\mathrm{C}-$ 6), 72.2 (C-5), 71.6 (C-4), 70.6 (C-3), 66.3 (C-7), $60.9\left(\mathrm{CH}_{2} \mathrm{CH}_{3}\right), 35.1$ (C-1'), 34.0 (C-2), 26.6 $\left(\left(\mathrm{CH}_{3}\right)_{2} \mathrm{C}\right), 26.0\left(\left(\mathrm{CH}_{3}\right)_{2} \mathrm{C}\right), 25.4\left(\left(\mathrm{CH}_{3}\right)_{2} \mathrm{C}\right), 24.8\left(\left(\mathrm{CH}_{3}\right)_{2} \mathrm{C}\right), 13.6\left(\mathrm{CH}_{2} \mathrm{CH}_{3}\right)$; ESI-MS: $\mathrm{m} / z$ $533.08[\mathrm{M}+\mathrm{Na}]^{+}$; Anal. Calcd for $\mathrm{C}_{25} \mathrm{H}_{31} \mathrm{FO}_{8} \mathrm{~S}$ (510.17): C, 58.81; H, 6.12\%. Found: $\mathrm{C}, 58.85$; $\mathrm{H}, 6.22 \%$.

Synthesis of compound 16b. To a stirred solution of $\mathbf{1 5 b}(0.214 \mathrm{~g}, 0.418 \mathrm{mmol})$ in $\mathrm{CH}_{2} \mathrm{Cl}_{2}(1.5$ $\mathrm{mL})$ glacial $\mathrm{AcOH}(6.0 \mathrm{~mL})$ and $\mathrm{H}_{2} \mathrm{O}(4.0 \mathrm{~mL})$, were slowly added. The reaction mixture was warmed to $50^{\circ} \mathrm{C}$ and stirred for $6 \mathrm{~h}$. After this time, the solvent was co-evaporated with toluene under reduced pressure to give a crude which was purified by flash column chromatography on silica gel (AcOEt:MeOH, 20:1) to give $\mathbf{1 6 b}(0.111 \mathrm{~g}, 62 \%)$ as a glassy solid. $[\alpha]_{25}{ }^{\mathrm{D}}+36.1(\mathrm{c} 1.7$, $\mathrm{CH}_{2} \mathrm{Cl}_{2}$ ); ${ }^{1} \mathrm{H}$ NMR $\left(400 \mathrm{MHz}, \mathrm{CDCl}_{3}\right): \delta 7.22-7.18\left(\mathrm{~m}, 2 \mathrm{H}, p-\mathrm{F}-\mathrm{C}_{6} \mathrm{H}_{4}\right), 6.96-6.92(\mathrm{~m}, 2 \mathrm{H}, p-\mathrm{F}-$ $\mathrm{C}_{6} \mathrm{H}_{4}$ ), 4.53 (bs, $1 \mathrm{H}$ ), 4.09-4.02 (m, 2H, H-3, H-4 o H-5), 3.97-3.89 (m, 3H, H-6, $\mathrm{CH}_{2} \mathrm{CH}_{3}$ ), 3.723.63 (m, 2H, H-7a, H-5 o H-4), 3.53-3.49 (m, 1H, H-7b), 2.96-2.93 (A part of an AB system, $J_{A B}$ $12.8 \mathrm{~Hz}, \mathrm{H}-\mathrm{l}^{\prime} \mathrm{a}$ ), 2.83-2.80 (B part of an AB system, $J_{B A} 12.8 \mathrm{~Hz}, \mathrm{H}-1^{\prime} \mathrm{b}$ ), 1.99-1.84 (m, 2H, H2a, H-2b), 0.94 (t, $\left.J 7.2 \mathrm{~Hz}, 3 \mathrm{H}, \mathrm{CH}_{2} \mathrm{CH}_{3}\right) ;{ }^{13} \mathrm{C}$ NMR (50MHz, $\left.\mathrm{C}_{6} \mathrm{D}_{6}\right): \delta 165.5(\mathrm{Cq}), 163.06$ (d, $J$ $\left.248.1 \mathrm{~Hz}, \mathrm{Cq}, p-\mathrm{F}-\mathrm{C}_{6} \mathrm{H}_{4}\right), 153.1(\mathrm{Cq}), 132.2$ (d, $\left.J 3.25 \mathrm{~Hz}, \mathrm{Cq}, p-\mathrm{F}-\mathrm{C}_{6} \mathrm{H}_{4}\right), 130.3$ (d, $J 8.35 \mathrm{~Hz}$, $\mathrm{CH}, p$-F-C $\left.\mathrm{C}_{6} \mathrm{H}_{4}\right), 102.3(\mathrm{Cq}), 95.2(\mathrm{Cq}), 72.9$ (C-5 o C-4), 69.4 (C-6), 66.6 (C-3), 66.2 (C-4 o C5), 64.1 (C-7), $61.7\left(\mathrm{CH}_{2} \mathrm{CH}_{3}\right), 36.4(\mathrm{C}-2), 33.6\left(\mathrm{C}-1^{\prime}\right), 13.8\left(\mathrm{CH}_{2} \mathrm{CH}_{3}\right)$; ESI-MS: $m / z 453.08$ [M $+\mathrm{Na}^{+}$; Anal. Calcd for $\mathrm{C}_{19} \mathrm{H}_{23} \mathrm{FO}_{8} \mathrm{~S}$ (430.10): C, 53.02; H, 5.39\%. Found: C, 53.08; H, 5.30\%.

Synthesis of compound 12b. To a stirred solution of $\mathbf{1 6 b}(0.074 \mathrm{~g}, 0.171 \mathrm{mmol})$ in THF $(2.0$ $\mathrm{mL}), 1.02 \mathrm{~mL}$ of $1 \mathrm{M}$ solution of $\mathrm{LiOH}(1.02 \mathrm{mmol})$ in $\mathrm{H}_{2} \mathrm{O}$ were added. The reaction mixture was warmed at $60^{\circ} \mathrm{C}$ for $2 \mathrm{~h}$ then $1 \mathrm{M}$ solution of $\mathrm{H}_{3} \mathrm{PO}_{4}$ was added to reach $\mathrm{pH}$. The solvent was co-evaporated with toluene under reduced pressure to give a crude which was suspended in AcOEt $(15.0 \mathrm{~mL})$ and filtered through a PTFE membrane (pore size $0.20 \mathrm{uM}$ ). The filtrate was concentrated to dryness to give $\mathbf{1 2 b}(0.066 \mathrm{~g}, 97 \%)$ as a glassy solid. $[\alpha]_{25}{ }^{\mathrm{D}}+9.2(\mathrm{c} 1.1, \mathrm{MeOH})$; ${ }^{1} \mathrm{H}$ NMR $\left(400 \mathrm{MHz}, \mathrm{CD}_{3} \mathrm{OD}\right): \delta 7.39\left(\mathrm{~m}, 2 \mathrm{H}, p-\mathrm{F}-\mathrm{C}_{6} \mathrm{H}_{4}\right), 7.07-7.03\left(\mathrm{~m}, 2 \mathrm{H}, p-\mathrm{F}-\mathrm{C}_{6} \mathrm{H}_{4}\right), 4.07-4.03$ (m, 2H, H-3, H-5), 3.92-3.88 (m, 1H, H-6), 3.80-3.77 (A part of an ABX system, $J_{A B} 11.2 \mathrm{~Hz}$, $J_{A X} 3.2 \mathrm{~Hz}, 1 \mathrm{H}, \mathrm{H}-7 \mathrm{a}$ ), 3.73 (dd, $J 8.8 \mathrm{~Hz}, J 0.8 \mathrm{~Hz}, 1 \mathrm{H}, \mathrm{H}-4$ ), 3.54-3.49 (B part of an ABX system, $J_{B A} 11.6 \mathrm{~Hz}, J_{B X} 6.4 \mathrm{~Hz}, 1 \mathrm{H}, \mathrm{H}-7 \mathrm{~b}$ ), 3.04-3.01 (A part of an AB system, $J_{A B} 13.2 \mathrm{~Hz}$, $1 \mathrm{H}, \mathrm{H}-1^{\prime} \mathrm{a}$ ), 2.99-2.96 (B part of an AB system, $J_{B A} 13.0 \mathrm{~Hz}, 1 \mathrm{H}, \mathrm{H}-1^{\prime} \mathrm{b}$ ), 2.01-1.99 (m, 2H, H- 
2a, H-2b); ${ }^{13} \mathrm{C}$ NMR (100MHz, $\left.\mathrm{CD}_{3} \mathrm{OD}\right): \delta$ 168.8, 164.4 (d, $J$ 246.2 Hz, Cq, $\left.p-\mathrm{F}-\mathrm{C}_{6} \mathrm{H}_{4}\right), 154.8$, 134.7 (d, $\left.J 3.0 \mathrm{~Hz}, \mathrm{Cq}, p-\mathrm{F}-\mathrm{C}_{6} \mathrm{H}_{4}\right), 131.9$ (d, $J$ 8.4 Hz, CH, $p-\mathrm{F}-\mathrm{C}_{6} \mathrm{H}_{4}$ ), 115.6 (d, $J 22.0 \mathrm{~Hz}, \mathrm{CH}$, $p$-F-C $\left.{ }_{6} \mathrm{H}_{4}\right)$, 103.8, 96.6, 74.9, 70.3, 67.6, 67.4, 65.3, 37.1, 34.2; ESI-MS: $m / z$ 401.1 [M - H]; Anal. Calcd for $\mathrm{C}_{17} \mathrm{H}_{19} \mathrm{FO}_{8} \mathrm{~S}$ (402.07): C, 50.74; H, 4.76\%. Found: C, 50.64; H, 4.83\%.

Synthesis of compound 15c. To a solution of $13(0.096 \mathrm{~g}, 0.355 \mathrm{mmol})$ in $\mathrm{CHCl}_{3}(1.5 \mathrm{~mL})$ dry pyridine $(1.0 \mathrm{~mL})$ and $\mathbf{1 4 c ^ { 3 0 }}(0.170 \mathrm{mg}, 0.426 \mathrm{mmol})$ were added. The mixture was warmed at $50^{\circ} \mathrm{C}$ and stirred for $2 \mathrm{~h}$. The reaction mixture was cooled at $\mathrm{rt}$, diluted with $\mathrm{CH}_{2} \mathrm{Cl}_{2}(40 \mathrm{~mL})$ and washed with a saturated solution of $\mathrm{NH}_{4} \mathrm{Cl}(2 \times 10 \mathrm{~mL})$. The organic phase was dried over $\mathrm{Na}_{2} \mathrm{SO}_{4}$ and concentrated to dryness to give a crude which was purified by flash column chromatography on silica gel (AcOEt:Petroleum Ether 1:6) to give 15c $(0.180 \mathrm{~g}, 97 \%)$ as a glassy solid. $[\alpha]_{25}{ }^{\mathrm{D}}-22.97$ (c $\left.0.48, \mathrm{CH}_{2} \mathrm{Cl}_{2}\right) ;{ }^{1} \mathrm{H}$ NMR $\left(400 \mathrm{MHz}, \mathrm{CDCl}_{3}\right): \delta 7.23-7.21(\mathrm{~m}, 1 \mathrm{H}, m-$ OMe- $\mathrm{C}_{6} \mathrm{H}_{4}$ ), 6.91-6.85 (m, 3H, m-OMe- $\mathrm{C}_{6} \mathrm{H}_{4}$ ), 4.65-4.61 (m, 1H, H-3), 4.40-4.37 (dd, $J_{4-3} 5.2$ $\left.\mathrm{Hz}, J_{4-5} 1.2 \mathrm{~Hz}, 1 \mathrm{H}, \mathrm{H}-4\right), 4.34$ (aq, $J 4.8 \mathrm{~Hz}, 1 \mathrm{H}, \mathrm{H}-6$ ), 4.08-4.01 (m, 2H, H-7a, H-7b), 3.96 (q, $\left.J 7.2 \mathrm{~Hz}, 2 \mathrm{H}, \mathrm{CH}_{2} \mathrm{CH}_{3}\right), 3.83$ (dd, $\left.J_{5-6} 7.6 \mathrm{~Hz}, J_{5-4} 2.0 \mathrm{~Hz}, 1 \mathrm{H}, \mathrm{H}-5\right), 3.79$ (s, 3H, $\left.\mathrm{OCH}_{3}\right), 3.30-$ 3.26 (A part of an AB system, $J_{A B} 12.8 \mathrm{~Hz}, \mathrm{H}-1$ 'a), 2.97-2.94 (B part of an AB system, $J_{B A} 12.8$ $\mathrm{Hz}, 1 \mathrm{H}, \mathrm{H}-1$ 'b), 2.43-2.38 (A part of an ABX system, $J_{A B} 16.0 \mathrm{~Hz}, J_{A X} 3.2 \mathrm{~Hz}, 1 \mathrm{H}, \mathrm{H}-2 \mathrm{a}$ ), 2.142.10 (B part of an ABX system, $\left.J_{B A} 15.8 \mathrm{~Hz}, J_{B X} 2.8 \mathrm{~Hz}, 1 \mathrm{H}, \mathrm{H}-2 \mathrm{~b}\right), 1.47$ (s, 3H, $\left.\left(\mathrm{CH}_{3}\right)_{2} \mathrm{C}\right), 1.39$ $\left(\mathrm{s}, 3 \mathrm{H},\left(\mathrm{CH}_{3}\right)_{2} \mathrm{C}\right), 1.36\left(\mathrm{~s}, 6 \mathrm{H},\left(\mathrm{CH}_{3}\right)_{2} \mathrm{C}\right), 0.96\left(\mathrm{t}, \mathrm{J} 7.2 \mathrm{~Hz}, 3 \mathrm{H}, \mathrm{CH}_{2} \mathrm{CH}_{3}\right) ;{ }^{13} \mathrm{C} \mathrm{NMR}(100 \mathrm{MHz}$, $\left.\mathrm{CDCl}_{3}\right): \delta 165.26(\mathrm{Cq}), 159.1(\mathrm{Cq}), 155.0(\mathrm{Cq}), 138.6(\mathrm{Cq}), 134.2(\mathrm{Cq}), 128.8(\mathrm{CH}, m-\mathrm{OMe}-$ $\left.\mathrm{C}_{6} \mathrm{H}_{4}\right), 123.5\left(\mathrm{CH}, m-\mathrm{OMe}-\mathrm{C}_{6} \mathrm{H}_{4}\right), 121.14\left(\mathrm{CH}, m-\mathrm{OMe}-\mathrm{C}_{6} \mathrm{H}_{4}\right), 115.0,113.5,109.6,109.2,102.1$, 94.1, 73.7 (C-6), 72.2 (C-4), 71.6 (C-5), 70.6 (C-3), $66.4(\mathrm{C}-7), 60.9\left(\mathrm{CH}_{2} \mathrm{CH}_{3}\right), 55.2\left(\mathrm{OCH}_{3}\right)$, $35.1\left(\mathrm{C}-1^{\prime}\right), 34.1(\mathrm{C}-2), 26.8\left(\left(\mathrm{CH}_{3}\right)_{2} \mathrm{C}\right), 26.1\left(\left(\mathrm{CH}_{3}\right)_{2} \mathrm{C}\right), 25.4\left(\left(\mathrm{CH}_{3}\right)_{2} \mathrm{C}\right), 24.9\left(\left(\mathrm{CH}_{3}\right)_{2} \mathrm{C}\right), 13.6$ $\left(\mathrm{CH}_{2} \mathrm{CH}_{3}\right)$; ESI-MS: $m / z 545.08[\mathrm{M}+\mathrm{Na}]^{+}$; Anal. Calcd for $\mathrm{C}_{26} \mathrm{H}_{34} \mathrm{O}_{9} \mathrm{~S}$ (522.19): C, 59.75; $\mathrm{H}$, $6.56 \%$. Found: C, 59.77; H, 6.66\%.

Synthesis of compound 16c. To a stirred solution of $15 \mathrm{c}(0.180 \mathrm{~g}, 0.335 \mathrm{mmol})$ in $\mathrm{CH}_{2} \mathrm{Cl}_{2}(1.5$ $\mathrm{mL})$ glacial $\mathrm{AcOH}(5.0 \mathrm{~mL})$ and $\mathrm{H}_{2} \mathrm{O}(3.0 \mathrm{~mL})$, were slowly added. The reaction mixture was warmed to $50^{\circ} \mathrm{C}$ and stirred for $6 \mathrm{~h}$. After this time, the solvent was co-evaporated with toluene under reduced pressure to give a crude which was purified by flash column chromatography on silica gel (AcOEt:MeOH, 15:1) to give $\mathbf{1 6 c}(0.104 \mathrm{~g}, 74 \%)$ as a glassy solid. $[\alpha]_{25}{ }^{\mathrm{D}}+30.2(\mathrm{c} 0.8$, $\mathrm{CH}_{2} \mathrm{Cl}_{2}$ ); ${ }^{1} \mathrm{H}$ NMR $\left(400 \mathrm{MHz}, \mathrm{CDCl}_{3}\right): \delta$ 7.23-7.19 (m, $\left.1 \mathrm{H}, m-\mathrm{OMe}-\mathrm{C}_{6} \mathrm{H}_{4}\right), 6.88-6.82(\mathrm{~m}, 3 \mathrm{H}, m-$ OMe- $\left.\mathrm{C}_{6} \mathrm{H}_{4}\right)$, 4.15-4.11 (m, 2H, H-3, H-4 o H-5), 4.02-3.95 (m, 3H, H-6, $\left.\mathrm{CH}_{2} \mathrm{CH}_{3}\right), 3.78-3.72$ (m, $3 \mathrm{H}, \mathrm{H}-7 \mathrm{a}, \mathrm{H}-4$ o H-5) 3.72 (s, 3H, $\mathrm{OCH}_{3}$ ), 3.59-3.55 (m, 1H, H-7b), 3.01-2.98 (A part of an AB systen, $\left.J_{A B} 13.2 \mathrm{~Hz}, 1 \mathrm{H}, \mathrm{H}-1^{\prime} \mathrm{a}\right), 2.87-2.84$ (B part of an AB system, $J_{B A} 13.2 \mathrm{~Hz}, 1 \mathrm{H}, \mathrm{H}-1^{\prime} \mathrm{b}$ ), 2.04-1.89 (m, 2H, H-2a, H-2b), 0.98 (t, $J$ 7.2 Hz, 3H, $\left.\mathrm{CH}_{2} \mathrm{CH}_{3}\right) ;{ }^{13} \mathrm{C} \mathrm{NMR}\left(50 \mathrm{MHz}, \mathrm{C}_{6} \mathrm{D}_{6}\right): \delta$ $165.9(\mathrm{Cq}), 159.0(\mathrm{Cq}), 153.8(\mathrm{Cq}), 137.6(\mathrm{Cq}), 129.1\left(\mathrm{CH}, m-\mathrm{OMe}-\mathrm{C}_{6} \mathrm{H}_{4}\right), 120.8(\mathrm{CH}, \mathrm{m}-\mathrm{OMe}-$ $\left.\mathrm{C}_{6} \mathrm{H}_{4}\right), 114.6\left(\mathrm{CH}, m-\mathrm{OMe}-\mathrm{C}_{6} \mathrm{H}_{4}\right), 114.2\left(\mathrm{CH}, m-\mathrm{OMe}-\mathrm{C}_{6} \mathrm{H}_{4}\right), 102.1(\mathrm{Cq}), 95.1(\mathrm{Cq}), 731$. $(\mathrm{C}-4 \mathrm{o}$ C5), 69.2 (C-6), 66.4 (C-3); 66.1 (C-5 o C-4), 64.3 (C-7), $61.4\left(\mathrm{CH}_{2} \mathrm{CH}_{3}\right), 55.3\left(\mathrm{OCH}_{3}\right), 36.0(\mathrm{C}-$ $\left.1^{\prime}\right), 33.3(\mathrm{C}-2), 13.6\left(\mathrm{CH}_{2} \mathrm{CH}_{3}\right)$; ESI-MS: $m / z 465.08[\mathrm{M}+\mathrm{Na}]^{+}$; Anal. Calcd for $\mathrm{C}_{20} \mathrm{H}_{26} \mathrm{O}_{9} \mathrm{~S}$ (442.12): C, 54.29; H, 5.92\%. Found: C, 54.32; H, 5.98\%. 
Synthesis of compound 12c. To a stirred solution of $16 \mathbf{c}(0.060 \mathrm{~g}, 0.142 \mathrm{mmol})$ in THF $(2.0$ $\mathrm{mL}), 0.852 \mathrm{~mL}$ of $1 \mathrm{M}$ solution of $\mathrm{LiOH}(0.852 \mathrm{mmol})$ in $\mathrm{H}_{2} \mathrm{O}$ were added. The reaction mixture was warmed at $60^{\circ} \mathrm{C}$ for $2 \mathrm{~h}$ then $1 \mathrm{M}$ solution of $\mathrm{H}_{3} \mathrm{PO}_{4}$ was added to reach $\mathrm{pH}$. The solvent was co-evaporated with toluene under reduced pressure to give a crude which was suspended in AcOEt:MeOH 8:1 (17.0 mL) and filtered through a PTFE membrane (pore size 0.20 uM). The filtrate was concentrated to dryness to give $12 \mathrm{c}(0.054 \mathrm{~g}, 92 \%)$ as a glassy solid. $[\alpha]_{25}{ }^{\mathrm{D}}+5.0$ (c 0.63, MeOH); ${ }^{1} \mathrm{H}$ NMR (400MHz, $\left.\mathrm{CD}_{3} \mathrm{OD}\right): \delta$ 7.24-7.20 (m, $\left.1 \mathrm{H}, m-\mathrm{OMe}-\mathrm{C}_{6} H_{4}\right), 6.96-6.78(\mathrm{~m}$, $\left.3 \mathrm{H}, m-\mathrm{OMe}-\mathrm{C}_{6} H_{4}\right), 4.12-4.05$ (m, 2H, H-3, H-5), 3.91-3.87 (m, 1H, H-6), 3.79-3.75 (m, 5H, H-4, $\mathrm{H}-7 \mathrm{a}, \mathrm{OCH}_{3}$ ), 3.58-3.53 (B part of an ABX system, $J_{B A} 11.2 \mathrm{~Hz}, J_{B X} 5.6 \mathrm{~Hz}, 1 \mathrm{H}, \mathrm{H}-7 \mathrm{~b}$ ), 3.033.00 (A part of an AB system, $J_{A B} 12.8 \mathrm{~Hz}, 1 \mathrm{H}, \mathrm{H}-1$ 'a), 2.99-2.96 (B part of an AB system, $J_{B A}$ $\left.12.8 \mathrm{~Hz}, 1 \mathrm{H}, \mathrm{H}-1^{\prime} \mathrm{b}\right), 2.01-1.99$ (m, 2H, H2a, H2b); ${ }^{13} \mathrm{C}$ NMR (50MHz, CD $\left.{ }_{3} \mathrm{OD}\right): \delta 169.7,160.5$, 154.1, 139.5, 129.8, 121.9, 115.3, 115.2, 104.4, 96.3, 74.7, 70.4, 67.6, 67.5, 65.2, 55.7, 37.2, 34.2; ESI-MS m/z 413.1 [M - H] ; Anal. Calcd for $\mathrm{C}_{18} \mathrm{H}_{22} \mathrm{O}_{9} \mathrm{~S}$ (414.09): C, 52.17; H, 5.35\%. Found: C, 52.07; H, 5.42\%.

\section{Enzyme inhibition assays}

The A/Mississippi/3/2001 wild type H1N1 influenza virus ${ }^{34}$ was used to evaluate susceptibility in an enzyme inhibition assays. $25 \mu \mathrm{l}$ of A/Mississippi/3/2001 wild type H1N1 influenza virus was mixed with $25 \mu \mathrm{l}$ of inhibitor (Zanamivir or 11 or 12a), and after preincubation for $30 \mathrm{~min}$ at room temperature $50 \mu \mathrm{l}$ of MUNANA was added. After $60 \mathrm{~min}$ at $37^{\circ} \mathrm{C}$ the reaction was stopped with the addition of $200 \mathrm{mM} \mathrm{Na} \mathrm{CO}_{3}$. Fluorescence units were quantitated with a BMG FLUOstar with an excitation wavelength of $365 \mathrm{~nm}$ and an emission wavelength of $450 \mathrm{~nm}$. Final concentrations in the assay were $50 \mathrm{mM}$ sodium acetate $\mathrm{pH} 5.5,5 \mathrm{mM} \mathrm{CaCl}_{2}$ and $100 \mu \mathrm{M}$ MUNANA. Serial 10-fold dilutions of Zanamivir were prepared in water. Dilutions of the compound 11 and 12a ranged from 10 to $10000 \mu \mathrm{M}$.

\section{Acknowledgements}

We would like to thank Sue Barrett for antiviral assays and Ente Cassa di Risparmio di Firenze for financial support.

\section{References}

1. Knall, A.C.; Slugovc, C. Chem. Soc. Rev. 2013, 42, 5131.

2. Beckmann, H. S. G.; Niederwieser, A.; Wiessler, M.; Wittmann, V. Chem. Eur. J. 2012, 18, 6548.

http://dx.doi.org/10.1002/chem.201200382

PMid:22511395 
3. Jiang, X.; Wang, R. Chem. Rev. 2013, 113, 5515.

4. Foster, R. A. A.; Wills, M. C. Chem. Soc. Rev. 2013, 42, 63. http://dx.doi.org/10.1039/c2cs35316d PMid:23079670

5. Sugano, M.; Sato, A.; Iijima, Y.; Oshima, T.; Furuya, K.; Kuwano, H.; Hata, T.; Hanzawa, H. J. Am. Chem. Soc. 1991, 113, 5463. http://dx.doi.org/10.1021/ja00014a053

6. Nandaluru, P. R.; Bodwell, G. J. J. Org. Chem. 2012, 77, 8028.

7. Devaraj, N. K.; Weissleder, R.; Hilderbrand, S. A. Bioconjugate Chem. 2008, 19, 2297. http://dx.doi.org/10.1021/bc8004446 PMid:19053305 PMCid:PMC2677645

8. Blackman, M.L.; Royzen, M.; Fox, M.J. J. Am. Chem. Soc. 2008, 130, 13518. http://dx.doi.org/10.1021/ja8053805 PMid:18798613 PMCid:PMC2653060

9. Zeng, D.; Zeglis, B. M.; Lewis, J. S.; Anderson, C. J. J. Nuc. Med. 2013, 54, 829. http://dx.doi.org/10.2967/jnumed.112.115550 PMid:23616581

10. Zeglis, B. M.; Mohindra, P.; Weissman, G. I.; Divilov, V.; Hilderbrand, S. A.; Weissleder, R.; Lewis, J. S. Bioconjugate Chem. 2011, 22, 2048. http://dx.doi.org/10.1021/bc200288d PMid:21877749 PMCid:PMC3197258

11. Jiang, X.; Wang, L.; Kai, M.; Zhu, L.; Yao, X.; Wang, R. Chem. Eur. J. 2012, 18, 11465. http://dx.doi.org/10.1002/chem.201201102 PMid:22829472

12. Cacciarini, M.; Menichetti, S.; Nativi, C.; Richichi, B. Curr. Org. Synth. 2007, 4, 47. http://dx.doi.org/10.2174/157017907779981570

13. Nandaluru, R. P.; Bodwell, G. J. J Org. Chem. 2012, 77, 8028.

14. Legnani, L.; Lunghi, C.; Albini, F. M.; Nativi, C.; Richichi, B.; Toma, L. Eur. J. Org. Chem. 2007, 3547.

15. Contini, A.; Leone, S.; Menichetti, S.; Viglianisi, C.; Trimarco, P. J. Org. Chem. 2006, 71, 5507.

http://dx.doi.org/10.1021/jo0604538

PMid:16839129

16. Wang, H.; Wang, Y.; Han, K. L.; Peng, X. J. J. Org. Chem. 2005, 70, 4910. http://dx.doi.org/10.1021/jo0479213

PMid:15960488

17. Sauer, J.; Heldmann, D. K.; Hetzenegger, J.; Krauthan, J.; Sichert, H.; Schuster, J. Eur. J. Org. Chem. 1998, 2885. 
18. Chen, W.; Wang, D.; Dai, C.; Hamelberg, D.; Wang, B. Chem Commun. 2012, 48, 1736. http://dx.doi.org/10.1039/c2cc16716f

PMid:22159330

19. Capozzi, G.; Menichetti, S.; Nativi, C.; Rosi, A.; Franck, R. W. Tetrahedron Lett. 1993, 34, 4253. http://dx.doi.org/10.1016/S0040-4039(00)60541-5

20. Capozzi, G.; Menichetti, S.; Nativi, C.; Simonti M. C. Tetrahedron Lett. 1994, 35, 9454.

21. Bartolozzi, A.; Pacciani, S.; Benvenuti, C.; Cacciarini, M.; Liguori, F.; Menichetti, S.; Nativi, C. J. Org. Chem. 2003, 68, 8529.

http://dx.doi.org/10.1021/jo034556r

PMid:14575481

22. Gabrielli, G.; Melani, F.; Bernasconi, S.; Lunghi, C.; Richichi, B.; Rollin, P.; Venturi, C.; Nativi, C. J. Carbohydr. Chem. 2009, 28, 124. http://dx.doi.org/10.1080/07328300902752223

23. Venturi, F.; Venturi, C.; Liguori, F.; Cacciarini, M.; Montalbano, M.; Nativi, C. J. Org. Chem. 2004, 69, 6153.

http://dx.doi.org/10.1021/jo049441h

PMid:15373507

24. Nativi, C.; Dragoni, E.; Richichi, B.; Roelens, S. in Synthesis and Biological Applications of Glycoconjugates; Renaudet, O.; Spinelli, N. Eds.; Bentham Science Publishers, 2011; p 240254.

25. Fragai, M.; Nativi, C.; Richichi, B.; Venturi, C. ChemBioChem. 2005, 6, 1345.

http://dx.doi.org/10.1002/cbic.200400456

PMid:15977273

26. Toma, L.; Di Cola, E.; Ienco, A.; Legnani, L.; Lunghi, C.; Moneti, G.; Richichi, B.; Ristori, S.; Dell'Atti, D.; Nativi, C. ChemBioChem. 2007, 8, 1646.

http://dx.doi.org/10.1002/cbic.200700208

PMid:17705308

27. Arcangeli, A.; Toma, L.; Contiero, L.; Crociani, C.; Legnani L.; Lunghi, C.; Nesti, E.; Moneti, G.; Richichi, B., Nativi, C. Bioconjugate Chem. 2010, 21, 1432.

http://dx.doi.org/10.1021/bc900557v

PMid:20669938

28. Jiménez-Barbero J.; Dragoni, E.; Venturi, C.; Nannucci, F.; Ardà, A.; Fontanella, M.; André, S.; Canada, F. J.; Gabius, H. J.; Nativi, C. Chem. Eur. J. 2009, 15, 10423.

http://dx.doi.org/10.1002/chem.200901077

PMid:19746469

29. Richichi, B.; Imberty, A.; Gillon, E.; Bosco, R.; Sutkeviciute, I.; Fieschi, F.; Nativi, C. Org. Biomol. Chem. 2013, 11, 4086.

http://dx.doi.org/10.1039/c3ob40520f

PMid:23673818 
30. Richichi, B.; Lunghi, C.; Papakyriakou, A.; Francesconi, O.; Nativi, C. Pure Appl. Chem. 2013, 85, 1803.

http://dx.doi.org/10.1351/PAC-CON-12-11-08

31. Haudrechy, A.; Sinay, P. J. Org. Chem. 1992, 57, 4142.

32. Wagner, R.; Matrosovich, M.; Klenk, H. D. Rev. Med. Virol. 2002, 12, 159.

33. Monto, A.S.; McKimm-Breschkin, J. L.; Macken, C.; Hampson, A. W.; Hay, A., Klimov, A.; Tashiro, M.; Webster, R. G.; Aymard, M.; Hayden, F. G.; Zambon, M. Antimicrob. Agents Chemother. 2006, 50, 2395.

http://dx.doi.org/10.1128/AAC.01339-05

PMid:16801417 PMCid:PMC1489772

34. Potier, M.; Mameli, L.; Belisle, M.; Dallaire, L.; Melancon, S. B. Anal Biochem. 1979, 94, 287.

http://dx.doi.org/10.1016/0003-2697(79)90362-2

35. Blick, T.J.; Tiong, T.; Sahasrabudhe, A.; Varghese, J. N.; Colman, P. M.; Hart, G. J.; Bethell, R. C.; McKimm-Breschkin, J. L. Virology 1995, 214, 475. 